\title{
Management Development Trends of Nowadays in Albania
}

\author{
Sonela Stillo, Eleni Vangjeli \\ University “Fan S.Noli”, Korca, Albania \\ Enton Stillo \\ American University “San Clement”, Ohrid, Macedonia
}

\begin{abstract}
Albanian business environment is defined by complexity, dynamism, uncertainty. In Albania, there are small and medium enterprises (businesses). Although we have a high degree of business bankrupt, many businesses are reinforcing their competitive positions in market. In these conditions, a new appropriate organizational structure often plays a crucial role in managing the challenges. While the firm grows, at the same time grows the need for organization, involvement and leadership. In today's changing times, effective leadership is a key component of organizational success. Even if management is the key of operation and the standard operating procedures, our study shows that the manager always need leader’s power. In today’s global marketplace, organizations that strategically focus on building leadership capacity for the future will reap the benefits in the years to come. New trends in business development, of course have increased requirements for local managers. The organizations are under pressure to show return on investment for training and development. Although positive trends, problems which management is faced are more challenging than the degree of preparation and performance that they offer, so their qualitative qualification remains the continuous preoccupation as the role of our school is in this direction. From this point of view, education in distance can be considered as complementary approach and in some conditions as a worthy replacement of direct education, which still dominates educative systems in Albania.
\end{abstract}

Keywords: management, structure, leadership, training, public, private, business

\section{Actual Situation of Albanian Macro-economic Indicators}

The wind of changes which involved Albania in 1991 as the communist system crashed saw a totally collapsed economy. This period brought the polarization of producing sectors, which resulted in a decline of the GDP up to $15 \%$, increase of unemployment and duplication of inflation. The difficult situation of changing the governing systems and transition from a centralized economy to market economy brought the need for reforms in the Albanian economy. In the beginning of 1990s, a series of reforms were undertaken concerning the privatization actions. If we recall the previous years, we can say that the Albanian economy until 1997 was satisfactorily growing and developing. It was in 1997 that a serious economic, political and social crisis affected Albania. It was the crisis of the pyramid schemes that resulted in an economic decline in 7\%, but above all brought the physical collapse of government institutions. Thus, the time to recover was too long. The story shows that the key to a

Sonela Stillo, Ph.D., Head of Department of Management, Economic Faculty, University “Fan S.Noli”.

Eleni Vangjeli, Ph.D., Department of Finance, Economic Faculty, University "Fan S.Noli”.

Enton Stillo, Manager and Master's Student in the American University "San Clement”, Ohrid, Macedonia.

Correspondence concerning this article should be addressed to Sonela Stillo, Rr “Dhori Luarasi”, Lgj.12, Nr.15, Korca, Albania. E-mail: sonelastillo@yahoo.com. 
political crisis can be found in political elections, in 3-6 months, while an economic crisis needs a long time to eliminate its effects and begin the economic recovery. In the coming years, the Albanian economy recovered as result of a macroeconomic stability and the existence of a smooth political environment. We could mention a fact due to the reforms brought absolute poverty alleviation from 33\% in 1998 to 19\% in 2005.

The reforms taken concerning the economic stability of the country and investment encouragement through fiscal facilities brought decrease of unemployment from $16.8 \%$ in 2000 to $13.78 \%$ in 2009 onwards. Table 1 shows the situation of macroeconomic indicators during 2000-2009 in Albania.

Table 1

Macro-economic Indicators During 2000-2009 (in \%)

\begin{tabular}{lcccccccccc}
\hline & 2000 & 2001 & 2002 & 2003 & 2004 & 2005 & 2006 & 2007 & 2008 & 2009 \\
\hline Increase of GDP & 6.7 & 7.9 & 4.2 & 5.8 & 5.7 & 5.8 & 6 & 6 & 8 & - \\
Inflation (index of consumer prices) & - & 3.1 & 5.3 & 2.4 & 2.9 & 2.4 & 2.4 & 2.9 & 2.2 & 3.5 \\
Unemployment & 16.8 & 16.4 & 15.8 & 15 & 14.4 & 14.1 & 13.8 & 13.5 & 13.2 & 13.78 \\
\hline
\end{tabular}

Note. Source: INSTAT.

\section{Characteristics of Management in Albanian Businesses}

The environment where the Albanian businesses acted has been under continuous changes since the economic, political, social-cultural and technological factors changed. The political changes of 1990s, transition from the centralized economy to an economy built on completely different principles we could not even imagine, were followed by everyone's wish to be part of the market economy. Nowadays, it is difficult for new management researchers to understand how a centralized extreme-type economy would work, where everything was directed from the Party and individuals were only "instrument" of the bureaucratic machine under degradation. Operating within the frame of an economy relied on collective property and the socialist relations which were present in the entire social life and directions from above were the priority for all. A characteristic feature in Albania was the lack of initiative expecting thus orders from the superior. Profit was considered secondary and not as promoter for the economic development of the country. In these conditions, no one could talk about the existence and the necessity of a management science neither about market-oriented management practices.

The Albanian economy, having industry as its priority, was changing its aspect passing from the production sector to that of services prioritizing the development of trade which was favored from its geographical position, the available resources and a poor market almost in each direction.

In such situation first businesses came to light. Few people could predict that the spirit of Albanian entrepreneur had so many good features in risk taking. They were adapted quicker than other countries' entrepreneurs although the later had more advantages in the start and were more open to the west world. They were far from the qualities possessed from the new Albanian entrepreneurs. Businesses within few years reached 40 thousand and actually are estimated more than 60 thousand businesses.

Already owner-managers should manage their businesses in completely different situations. They should pass from a total security to ongoing risk situations; from decisions coming from above to participatory decision making; from production oriented to customer oriented; from administration to creative management.

All these new main features required essential and considerable changes in knowledge, information, skills, behavior so that they could become successful professional managers.

During the transition years, along with progressive changes, yet it presents a commanding management style 
which is closely related to the near past of Albania and to the development level and cultural traditions as well.

Albania, like the other transitional countries, is left behind from the western countries concerning the real understanding of the term "management”. Also, management and the entrepreneurship skills are still considered as resources less efficient than the capital in a moment when management and entrepreneurship play a crucial role in business success and performance. As time goes by, the capacities of human resources as a whole and more specifically, considered as the main factors for making the organization are more competitive. It has been experienced many times from the Albanian practice that between the effective management, its competitiveness and organizational success exist a "cause-effect” relationship. Increase of organization's competitiveness, improvement of productivity and development of human and management capacities should be indivisible.

For many reasons, and because of high demands of market for different goods and services, many Albanian businesses in their start up period saw only success. Their satisfactory profits served as de-motivators in two main aspects: (1) In management know-how which was considered as unnecessary; and (2) In business structure relied upon their poor knowledge and bad experience inherited from the government enterprises. But, increase of competitiveness, government control over market as well as market openness-giving space to foreign businesses and thus a stronger competition — made many businesses to close, and others tried to adopt new demands and those that just started tried to learn from good and bad experiences of the past. In today's literature causes of business failure, there often analyzed and discussed in a broad range of factors such as insufficient sales, low profit, high expenses on economic activities, frauds, etc.. By carefully analyzing these factors we could draw the conclusion that there are two main reasons of business failure in Albania: limited financial capacity and lack of management expertise.

In Albania, like in other Eastern countries, main businesses are small and middle sized. Definition for SMEs in Albania is similar to that in Europe, but there are differences because of economic dimensions and performance.

Contribution of small and medium enterprises consists of four main directions:

- The backbone of market economy;

- Produce for the domestic market;

- Increase the employment rates;

- Bring flexibility in economy.

Thus, having such dominant role in the country's economic growth these businesses have made dominant also their form of organizing, managing and monitoring/controlling.

The main businesses are concentrated on trade and other services, construction industry, dress making, foodstuff processing, etc.. The entrepreneur, who is managing the activity of the firm/company, generally is not educated in economics, accounting or finance.

Because of the fact that the entrepreneurs' class in Albania is not able to know the need and the role of an effective management, there are applied only simple elements of management.

The Albanian businessmen, together with his/her ownership right, are generally exercising the main role in management process of his/her business. In other words, in Albania, there is no clear distinction between the ownership right and managing function. This is linked with large percentage of micro businesses (micro firms), where the owner is doing by himself the managing function. The owners hesitate to give the managing right of their firm to "a foreign" person. According to our survey, the majority of the businessmen forecast to extend their activity, but even in this case, they are thinking to play the main role in the managing process of the firm, or they 
will believe to give some managing right to their trusted persons.

Two most important decisions that will be taken by any organization/company are: (1) What will be the level of decentralization of the organizational structure; (2) What kind of decisions will be delegated to the subordinates? Nowadays, the Albanian economy is entering the phase of consolidating contemporary structures of the market economy. The growing process is evident not only in quantitative aspect, but also the quality of production and service is going to increase, too. These changes will have great need for the opinion and help of the qualified specialists. Coping effectively with the competition in the market requires, among the other things, the decentralization of the organizational structures, as well as, the delegation of the authority to the subordinates.

The above aspects are linked also with the organizational culture of a company. This will not be seen separately from the culture and the environment traditions in which the employees are living. In general, the Albanian society will be classified as a society based on the patriarchal type of the family. Is such mentality, which is giving the influence in the relations within an organization?

As the above are concerned and keeping on with our analysis, we can say that the achievement of a high performance, being as essential task to every manager, in simple words means that the manager should be not only effective and efficient in his/her work, but also should be guided from long term objectives for being competitive in market, thus to possess the skills of a leader. With the popular image, leaders were viewed as masters of all the knowledge. They deny fear and are self-sufficient. One who doubts about that is soon wiped off.

Analyzing this mentality, we can understand that leader is supposed to be the one that comes out of the crowd only in the moments of radical change. As far as here, the popular image is mainly in compliance with the modern theories of leader as head of change. But the notion stops here. It sees the leader as the effective factor only on drastic change. Thus, it is difficult to transfer the political or social concept in organizational life. Albanian mentality finds that it is difficult to identify a leader who is at the head of everyday changes, who doesn't expect a war or a revolution to become "alive", who has his/her own doubts and need to grow like every other person at the world. This kind of person is mostly considered as an unstable individual, who doesn't know what he wants, etc..

This mentality was heavily strengthened during the communist period, when leaders were the materialized god on earth, in whom people had to believe and obey blindly, and sing songs and adore, by order.

Understanding that leaders are human who need to grow, who suffer and learn is the first point to the difficult way of understanding the complex phenomenon of leadership. It is the way a leader can step down the pedestal of worship, and become one of us, who can be encountered in everyday life of our organizations. It is the only way we can try to start teaching leadership, and make people consider their capabilities not only as followers. Leadership is easy to explain but not to practice.

If we want to make an analysis of leadership, we may say that today's organization life in Albania needs leaders with vision. In the present conditions, vision means managing the relations with other powerful organization as well as with developed countries. Today's organization life in Albania needs realistic leaders who can size up economic problems in terms of specific conditions of the country, without surrender to corruption and bureaucracy. This of course demands for courageous leaders, characterized by determination and perseverance that know what patriotism is.

All the activities of the leader can't be complete if he/she is not ethic. Today, leadership ethics are more important than ever. The guarantee of the ethic community requires the existence of three elements: individuals that act in an ethical way, company's ethical leadership, and appropriate structure/policies in order to support employees' projects that act according to ethics. Many business companies have approved written ethical 
codes, which help the employees in this direction. But the question posed is whether the managers-leaders of our companies are ethic.

Only a small numbers are involved in ethic cases whereas the rest are very strict, act only by the rules placed by the organization and according to the laws, and never cross these boundaries. They are always enclosed inside a box full of rules and never go outside it ("absolutely according to the law"-as some of them approved).

But a question rises about the characters that determine the ethical boundaries in an organization. Are they determined by the high management, ethics committee, managers themselves or owners? So, $40 \%$ of the interviewers believe that the boundaries should be established by the high management, and $18 \%$ believe that it is the duty of ethics committee. Therefore, according to them, those who are responsible for the plans and procedures of the organization should also be responsible for the boundaries of ethics.

Being ethical is still seen as a premature requirement by the Albanian organization leader. Coming from the planned economy where the word "profit" did not exist, the private business has embraced with all its potential, the concept of profit to by all means. This of course gives life to unethical behavior inside the organization as well as of it.

\section{Results and Discussion About Improving Management Performance of Albanian Businesses-A Necessity for Their Successful Business Development}

The Albanian economy began its transformation process when "the wind of changes” started to give the first advantages in other central and eastern European countries. In Albania, this process began in such environment of extreme economic centralization where managers of all levels lack even the most elementary knowledge of market economy management.

Unfortunately, most of managers—no matter they were from public or private sector—began this "new job” without asking themselves or the government to provide training on new management knowledge. They thought that this new economy would not be demanding and challenging which was something difficult for them to face efficiently and effectively.

In this re-dimensioned context where businesses operate, according to many management researchers, today is the time when professionalism is mostly required as an essential precondition for a high performance. At the same time, change is perceived as an inseparable part of the way of living and employees are required to offer new ways in order to achieve high productivity in new and dynamic conditions. They are expected to be more involved, participate in issues that affect the organization, show creativity and devotion to their work.

All these trends as well as new treatments for management and its role, require a new way of thinking from individuals who work in an organization, and in this context, demands are higher especially to the managers.

New trends in the Albanian business development increase the demands for domestic managers. In adapting themselves to these business challenging dimensions, managers have some advantages:

- There exists already such experience gained during two decades of market economy in management;

- Higher level of preparing the managers in our schools - which is in an ongoing process of qualitative improvement of preparation standards of specialists;

- Greater presence of specialists returned after having completed their studies abroad. The government is using more and more stimulating policies for their return to Albania;

- Besides, the presence of foreign companies in the Albanian market offering thus a stronger competition makes the domestic managers to have higher demands in their individual preparation and get positive elements 
from their working culture and professionalism. We should not forget that many individuals have been employed in such companies in Albania and abroad which means that more specialists are qualified and are suitable to business demands in today's management.

Nevertheless the positive trends, problems that management faces are more challenging than the general level of preparation and performance they offer. Therefore, their qualitative qualification is a permanent concern such as the consolidation of school in this context.

Considering the training market in all its dimensions, we should emphasize that not only high and middle managers must be considered, bit lower managers as well who make up a considerable number. Here we should take into account the fact that their movement or substitution of those who are in managerial positions in the public sector happened often and is going to be as such for some time. This circulation will be reduced more as the politics and the Albanian society is civilized in adaption to European standards.

Thinking about an effective training in the private sector was growing simultaneously with the fragile state consolidation, strengthening the supervision and building the new legal framework. But the most important thing in this aspect was the role of competition law on business practices and failure-an unknown phenomenon in the beginning of their businesses.

As mentioned above, characteristic for most manager-owners in the private sector is the fact that they run their businesses themselves. Generally, these business managers do not make any distinction concerning their position in the management hierarchy. Most of the owners of these businesses act as business managers too performing all tasks and functions of all levels managers.

The predominating age of business managers varies from 30-39 years old. This fact is the result of a study conducted on the analysis of reforms effectiveness in public management using thus a comparative analysis among public and private sectors.

A sample of about 500 questionnaires was used in the above-mentioned study, divided equally in 250 questionnaires to the public administration and 250 ones to private businesses. Our research was conducted in main towns of Albania. To complete the research, there was a multi-phase selection to businesses.

In the first phase, towns where the study would be conducted were selected. For this reason, bigger towns in Albania were selected.

In the second phase, based on the number of businesses, questionnaires were distributed according the selected towns.

The third phase selection of businesses in each town was made. This distribution was based on a systematic selection and as data on number of employees were missing, private businesses were classified according their annual turnover.

From the analysis, we got the result that the average age of the respondents in the public administration is 39.30 years old, against 38.71 years old in the private businesses. It is a fact that in Albania has been applied simple management elements as entrepreneurs until lately did not consider their necessary training and need for an efficient management. This shows that in private sector, there exists the larger training market.

As far as managers' qualification is concerned, we can say that in private businesses, qualification training is performed at a certain level. This is confirmed from $45 \%$ of the respondents of private businesses. If we go on with the analysis, we can see that during the five last years in the public administration, the respondents were trained 4.13 times, whereas in private businesses approximately 3.87 times. If we compare the sectors the percentage will be a little higher in private businesses. This is justifiable if we accept the changes which business 
faces every day. The same thing we can say even for the frequency of trainings concernes the professional growth of managers (see Figure 1).

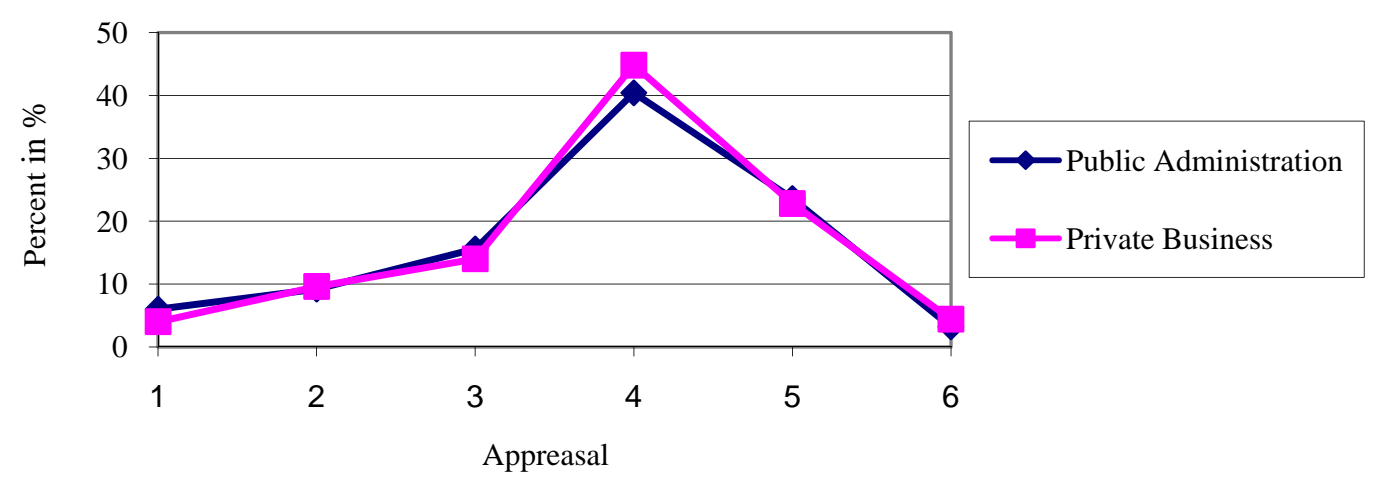

Figure 1. Frequency of trainings in the public administration and private businesses.

Nevertheless the above indicators, what is to be carefully noticed is how do the trainees estimate the efficiency of training. In an estimating level from 1 to 10 , in the public administration, the training efficiency is estimated 7.04 and in private businesses 7.16 (see Figure 2).

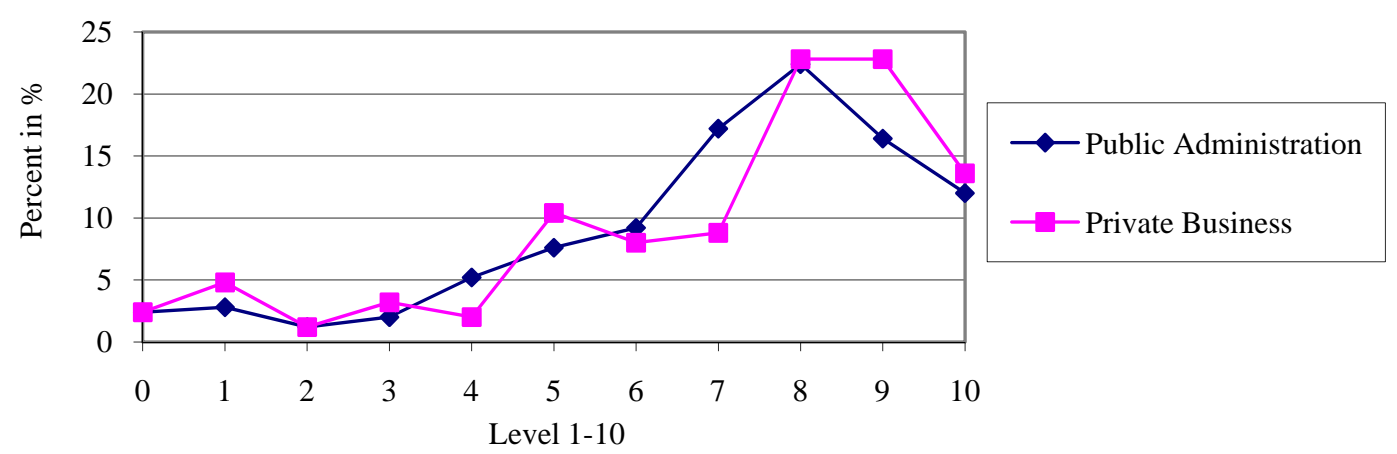

Figure 2. The training efficiency in the public administration and in the private business.

We would like to have a higher estimation on training, but we are still far from understanding its authentic importance. In many cases, training is considered as a reward for a good job or as an exchange of reciprocal favors. We think that a deficiency of this process is the lack of measuring the validity of training which often fades its importance.

From our study, the result shows that in both sectors, the highest percentage of respondents have not taken any training course abroad and outside their own town. This is more typical for the private businesses where entrepreneurs are not very interested to spend for training their specialists and managers especially in small and medium businesses.

Only $9 \%$ of them in the public administration have been often trained abroad, and $11.6 \%$ in private businesses, which is a figure about $2 \%$ higher than the public administration. We emphasize that this figure should be considered reservedly for coming to conclusion that private business has paid more attention to abroad training.

As we talk about the professional level of the Albanian managers, it is naturally related to their background, and the level of politics intervention in managers' appointed duties. They not only begin a new and unknown job without being sufficiently prepared, but do not show seriousness to the professionalism and the level of preparation required to them as well. Most of them, instead of being involved in increasing their professional and 
managerial level, considered their job as a profitable position not only from the material point of view (cases like that are many). They saw it as a means for professional carrier without relying on their qualification through training and individual study, but mostly by being involved in politics and relating to influential people of high government levels.

Although much has been talked about meritocracy, often the efficient person is not found in the right place and time. In an estimation level from 1-10 about the meritocracy in public employment, it was noticed that the interviewees in the public administration estimated meritocracy with an average of 5.83, while private business estimated it as 5.29, so, near the average values.

In most public institutions and companies, there exists the frequent movement of managers. It is a fact that movements of main managers from their positions have been frequent. The last 10 years main managers in public administration have been changed 3 times, while there is a greater stability in the private businesses where managers are changed 1.28 times on average. Thus, it can be noticed a greater stability of managers in private businesses, compared to public ones. Also, it is a significant fact that the average durability of public managers is 4.3 years, against 6.5 years of durability of managers in private businesses.

If we talk about the preparation level of the Albanian managers, it stands below the average level. This shows that specialized institutions should do a huge work. It may be a specialized management institution.

The environment where businesses operate today is different from that of the first transition years. The competition has been strengthened and the law on bankrupt is more active than in other countries. On the other side, the longeval world practice and the new business practice also showed that business failure risk is very high especially during 5-6 first years of their life. Actually, many Albanian businesses find themselves in such a critical point of their existence. The risk for failure follows them in every step they take. One of the main factors for failing the Albanian businesses (which is higher than the average of other countries according the domestic specialists) is thought to be deficiencies in the managerial background of entrepreneurs. The Albanian entrepreneur is characterized as an individual of middle educational level unequipped with the right knowledge and training in management.

The situation is promising in educating the managers and directors of institutions. To get information about the educational level of the respondents we specified four education categories: middle technical, middle general, university and post graduate.

Thus, the majority of them, about 78\%, have university degrees, $17 \%$ post-graduate, $3 \%$ middle general and $2 \%$ middle technical. Meanwhile, as private businesses are concerned, there are $64 \%$ respondents with university degrees, $19 \%$ middle school, $9 \%$ post graduate and $8 \%$ middle technical.

The results show clearly an advantage of the public administration in employing managers having high education and post graduate compared to private businesses. However, the figure $64 \%$ in private businesses shows its awareness in evaluating the intellectual and professional capacities to face the global economy challenges and the rules of the game in the capitalist world.

As the business employees show, an increase in the middle education level is not the same for those who own businesses. Nevertheless, the fact that the owners employ more specialists with higher education shows that they not only know better the rules of the game in market, but are becoming more aware that the capacities of human resources are necessary for being successful in an already open and more professional competition.

Thus, on the one hand, it is thought to be a wide investment program in the framework of the stability pact, and on the other, there is an unqualified and unmotivated range of managers in the public administration and a 
highly motivated range of managers in the private sector but having poor demands about their qualification which actually shows deficiencies.

Figure 3 shows the salary as a motivating factor for all of the employers in the public and private sector.

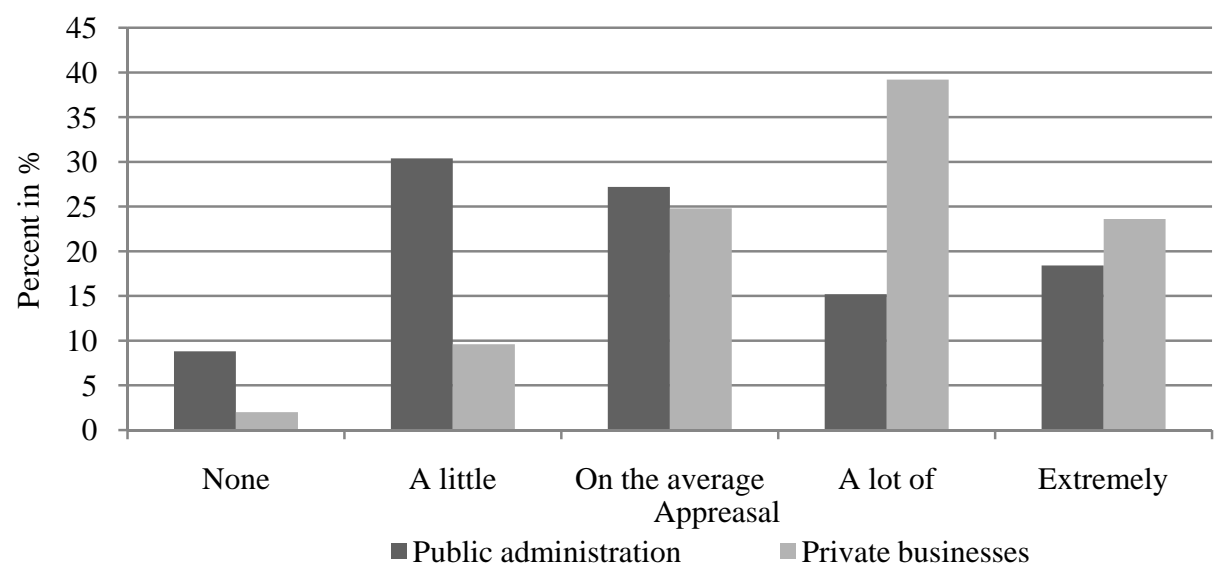

Figure 3. Salary as a motivating element for all of the employers in the public administration and in the private businesses.

Here we can see the advantages of private businesses in giving more satisfactory and motivating salaries compared to the public administration. This explains the fact why employees go to work in private businesses where opportunities are more. But such thing could not be generalized. Many individuals keep on working in the public administration, central or local, because they have inner needs for a higher status which serve as motivators for meeting the highest needs, although they could meet very well the lowest needs for themselves and their families by working in private businesses. From this point of view, we can affirm that government has one more obligation to keep these individuals as specialists or in managerial positions by using the best material incentives. This way of acting would serve as the greatest motivator in modifying their behavior which would reflect in higher and qualitative performance.

For the main businesses managers the situation is presented in Figure 4.

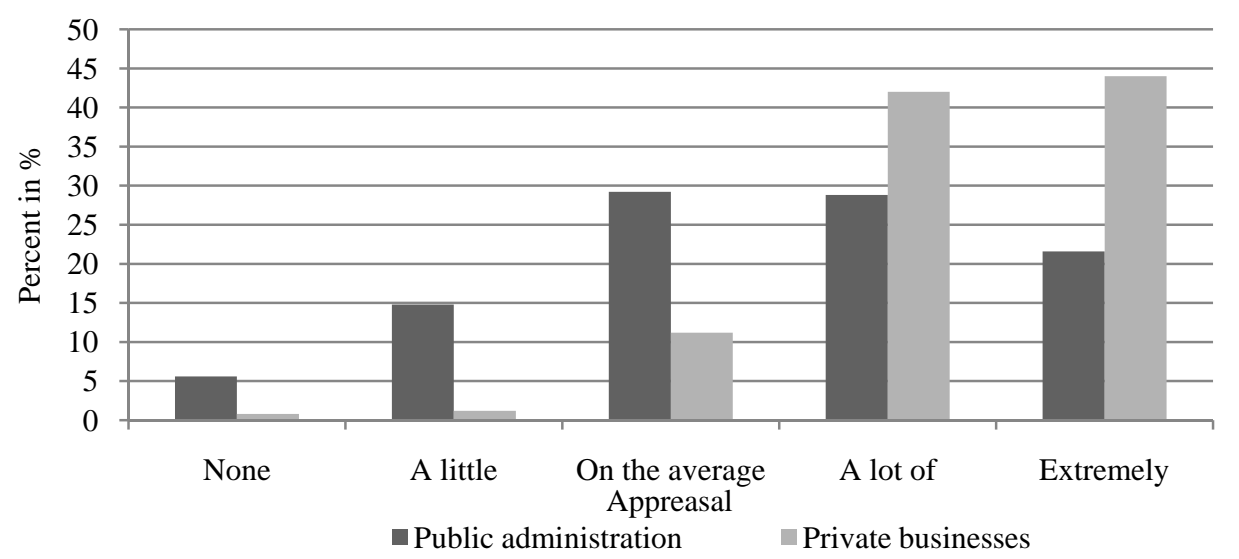

Figure 4. Salary as a motivating element for managers in the public administration and private businesses.

From Figure 4, we see that as far as managers are concerned, private businesses are in advantage to public administration. This explains the tendencies of the reforms in public management for applying new public management. 
These deficiencies require a serious and quick involvement of training institutions considering a wider range of organizations such as NGOs, science and educational institutions even establishing a management institution because the burden to hold needs a skillful expert staff, a platform and strategy where to consider two aspects: On the one hand, the future development strategy of the country; and on the other, the high training needs especially those of the higher and middle managers of the public and private sector as well.

\section{Conclusions}

The results of the economic reform showed that, among other things, the level of the development of the human resources in general, and the professional quality of the Albanian managers particularly are important factors with a strong impact on the rates and the level of success of the social and economic progress. On the other hand, one of the main factors of bankruptcy of the Albanian businesses is the lack of managerial knowledge.

There are more than 60 thousand businesses, whose owner-managers need management training. Besides designing trainings that consist in: training for legal issues, institutional management, specific trainings for management and leadership we should find ways to evaluate the training programs.

To gain support, the leader should demonstrate the values and vision of its supporters. People need to be encouraged to develop, learn and take responsibilities that they can handle. For people to embrace and follow honest, ethic, modern, peaceful and right laws, they should find these qualities reflected by their leaders. It is very important to select the right people for the right job. This is even more important than developing a strategy. Leaders should overcome the barriers and leadership fear and give themselves and others time to get to know each other. Leaders-managers should do more than just manage and lead. They should be a model of the behavior they want to see adopted.

The broad program of investments in the frame of the stability pact requires a class of managers qualified and motivated properly. This situation requires a serious and quick involvement of different training institutions in the managers' market. In this framework, the presence of specialized management institutions is more than necessary. The training organizations should take into consideration two main aspects: the strategy of future development of the country, and at the same time, the big training demand mainly of the high and middle level managers of the private and public sector.

The preparation of manager-leaders should be done based on a very carefully designed training program that takes into consideration the specifics of areas covered by the private sector. This initiative can't be successful if there is no cooperation with universities that not only have the intellectual resources (capacities) and expertise in these areas that represent fields of reciprocal interest.

We think that training programs that focus on management change and leadership transformation as a crucial element of reform need to be supported and promoted.

\section{References}

Burke, R., \& Cooper, C. L. (2003). Leading in turbulent times. Oxford Blackwell.

Cooper, C. (2005). Leadership and management in the 21 century. Oxford university Press.

Hal, G. R., \& Chun, Y. H. (2007). Public and private management compared. The Oxford Handbook of Public Management.

Llaci, S. (2008). Menaxhimi dhe organizata e biznesit. AlbPaper, 61-74.

Lloyd, L. B., \& Leslie, W. R. (2006). Human resource management. McGraw-Hill Irwin, 164-166, 222-233.

Samuel, C. C., \& Certo, S. T. (2009). Modern management. Prentice Hall, 362-382.

Wayne, F. C. (2006). Managing human resources: Productivity, quality of work life, profits. McGraw-Hill Irwin, 415-427. 